\title{
Using VIIRS to Provide Data Continuity with MODIS
}

\author{
Robert E Murphy ${ }^{1}$, William L Barnes, Alexei I Lyapustin ${ }^{3}$, Jeffrey Privette ${ }^{3}$, Carol \\ Welsch $^{4}$, Frank DeLuccia ${ }^{5}$, Hilmer Swenson ${ }^{5}$, Carl F Schueler ${ }^{6}$, Philip E Ardanuy ${ }^{7}$, Peter \\ S M Kealy ${ }^{7}$
}

\author{
${ }^{1}$ NASA Goddard Space Flight Center, Greenbelt, MD, USA \\ Tel: 301 614-5827.e-mail:murphy@LTPMail.gsfc.nasa.gov \\ ${ }^{2}$ NASA Goddard Space Flight Center, Greenbelt, MD, USA \\ ${ }^{3}$ Univerity of Maryland, Baltimore, MD, USA \\ ${ }^{4}$ The Integrated Program Office, Silver Spring, MD, USA \\ ${ }^{5}$ Aerospace Corporation, Silver Spring, MD, USA \\ ${ }^{6}$ Raytheon Santa Barbara Remote Sensing, Santa Barbara, CA, USA \\ ${ }^{7}$ Raytheon Information Technology and Scientific Services, Lanham, MD, USA
}

\begin{abstract}
Comparisons are made between the key properties of the MODIS and VIIRS sensors.
\end{abstract}

\section{INTRODUCTION}

Long-term continuity of the data series being initiated by the MODIS (MODerate Resolution Imaging Spectroradiometer) on NASA's Terra mission will be obtained using the VIIRS (Visible Infrared Imaging Radiometer Suite) flying on the converged National Polar-Orbiting Environmental Satellite System (NPOESS) and on the NPOESS Preparatory Project (NPP). The data series include critical parameters such as cloud and aerosol properties, vegetation index, land use and land cover, ocean chlorophyll and sea surface temperature.

VIIRS is being designed and built by Raytheon for the Integrated Program Office (IPO), the DoD, NOAA and NASA consortium that is responsible for NPOESS. In addition to meeting the requirements for operational environmental monitoring, VIIRS will meet the needs of the global change research community through the use of state-of-the-art algorithms and calibration and characterization activities.

\section{SPECTRAL BANDS}

VIIRS covers the spectral range from 0.4 to $12 \mu$ in 22 spectral bands. Spatial resolution ranges from 341 to 742 meters at nadir. Unlike MODIS, the VIIRS is designed to minimize pixel growth over the ground track using a pixel aggregation approach. The ground swath is $3,000 \mathrm{~km}$, permitting global daily coverage.

The reduction in the number of spectral bands from 36 to 22 results primarily from the elimination of MODIS bands used in atmospheric sounding, precipitable water, and ocean fluorescence. Additional capability is provided through the use of dual gains in 7 bands.

A more complete description of VIIRS is given in presentations by Welsch et al. (A NextGeneration Operational Sensor for NPOESS: The VIIRS (Visible Infrared Imaging Radiometer Suite)) in the Instrumentation and Future Technologies session.

In the Vis/NIR region, the 16 MODIS bands have been replaced by 9 VIIRS bands. See Table 1. MODIS bands 17-19 that are used to measure precipitable water, bands 13 high and 14 that are used to measure ocean chlorophyll fluorescence, and band 11 that is used in ocean color

Table 1 Vis/NIR Bands Compared

\begin{tabular}{|c|c|c|c|c|c|}
\hline \multicolumn{3}{|c|}{ VIIRS } & \multicolumn{3}{|c|}{ MODIS } \\
\hline $\begin{array}{l}\text { Band } \\
\text { Name }\end{array}$ & $\begin{array}{l}\text { Band } \\
\text { Ctr }\end{array}$ & $\begin{array}{l}\text { Band } \\
\text { Width }\end{array}$ & $\begin{array}{c}\text { Band } \\
\#\end{array}$ & $\begin{array}{c}\text { Band } \\
\text { Ctr }\end{array}$ & $\begin{array}{l}\text { Band } \\
\text { Width }\end{array}$ \\
\hline $\mathrm{M}^{*}$ * & $412 \mathrm{~nm}$ & $20 \mathrm{~nm}$ & 8 & $412 \mathrm{~nm}$ & $15 \mathrm{~nm}$ \\
\hline M2* & $445 \mathrm{~nm}$ & $18 \mathrm{~nm}$ & 9 & $443 \mathrm{~nm}$ & $10 \mathrm{~nm}$ \\
\hline M3* & $488 \mathrm{~nm}$ & $20 \mathrm{~nm}$ & $\begin{array}{l}10 \\
3 \\
\end{array}$ & $\begin{array}{l}488 \mathrm{~nm} \\
469 \mathrm{~nm}\end{array}$ & $\begin{array}{l}10 \mathrm{~nm} \\
20 \mathrm{~nm}\end{array}$ \\
\hline M4* & $555 \mathrm{~nm}$ & $20 \mathrm{~nm}$ & $\begin{array}{l}12 \\
4 \\
\end{array}$ & $\begin{array}{l}551 \mathrm{~nm} \\
555 \mathrm{~nm}\end{array}$ & $\begin{array}{l}10 \mathrm{~nm} \\
20 \mathrm{~nm}\end{array}$ \\
\hline $\mathrm{II}$ & $645 \mathrm{~nm}$ & $50 \mathrm{~nm}$ & 1 & $645 \mathrm{~nm}$ & $50 \mathrm{~nm}$ \\
\hline M5* & $672 \mathrm{~nm}$ & $20 \mathrm{~nm}$ & 13 & $667 \mathrm{~nm}$ & $10 \mathrm{~nm}$ \\
\hline M6 & $751 \mathrm{~nm}$ & $15 \mathrm{~nm}$ & 15 & $748 \mathrm{~nm}$ & $10 \mathrm{~nm}$ \\
\hline$M 7^{*}$ & $865 \mathrm{~nm}$ & $39 \mathrm{~nm}$ & 16 & $870 \mathrm{~nm}$ & $15 \mathrm{~nm}$ \\
\hline 12 & $865 \mathrm{~nm}$ & $39 \mathrm{~nm}$ & 2 & $859 \mathrm{~nm}$ & $36 \mathrm{~nm}$ \\
\hline
\end{tabular}

* Dual gain 
measurements are not matched in VIIRS. But 6 of the 7 moderate resolution (or radiometric) bands have dual gains, which permits their use over both land and ocean. Thus bands M3 and M4 are part of the essential set of ocean color bands and they fulfill the role of MODIS bands 3 and 4, the 500-meter land imaging bands. VIIRS imaging bands $I 1$ and 12 provide the functionality of the high-resolution MODIS bands 1 and 2. Spatial resolution of the VIIRS and MODIS bands are compared in Table 4 .

In the short-wave and mid-wave infrared (SWIR/MWIR) 11 MODIS bands have been replaced by 8 VIIRS bands. See Table 2 . One of them, 13 duplicates the wavelength of M10 but with higher spatial resolution and lower radiometric accuracy so that effectively only 7 VIIRS bands provide unique spectral information. The reduction in the number of bands is met through the dropping MODIS bands $24,25,27$ and 28, which are used for atmospheric sounding. On NPP and NPOESS, the sounding EDRs are assigned to the Crosstrack Infrared Sounder (CrIS). Additionally, MODIS band 22 at $3.96 \mathrm{~m}$ is replaced by VIIRS band M12, the analog of MODIS band 20 at $3.75 \mu$. The combination of bands at $3.75 \mu$ and $4.05 \mu$ are similar to the MODIS approach to MWIR sea surface temperature retrieval. Dual gain capability of M13 allows VIIRS to match the role of MODIS band 21 for fires.

In the long wave infrared (LWIR) region 8 MODIS bands are replaced by 4 VIIRS bands. See Table 3 . The primary difference is due to the

Table 2 SWIR/MWIR Bands Compared

\begin{tabular}{|l|cc|c|c|c|}
\hline \multicolumn{3}{|l|}{ VIIRS } & \multicolumn{3}{l|}{ MODIS } \\
\hline Band & Band & Band & Band & Band & Band \\
Name & Ctr & Width & $\#$ & Ctr & Width \\
\hline M8 & $1.24 \mu$ & $0.020 \mu$ & 5 & $1.24 \mu$ & $0.020 \mu$ \\
\hline M9 & $\begin{array}{c}1.378 \\
\mu\end{array}$ & $0.015 \mu$ & 26 & $\begin{array}{c}1.375 \\
\mu\end{array}$ & $0.030 \mu$ \\
\hline M10 & $1.61 \mu$ & $0.06 \mu$ & 6 & $1.64 \mu$ & $0.02 \mu$ \\
\hline I3 & $1.61 \mu$ & $0.06 \mu$ & NA & & \\
\hline M11 & $2.25 \mu$ & $0.05 \mu$ & 7 & $2.13 \mu$ & $0.05 \mu$ \\
\hline M12 & $3.70 \mu$ & $0.18 \mu$ & 20 & $3.75 \mu$ & $0.18 \mu$ \\
\hline I4 & $3.74 \mu$ & $0.38 \mu$ & NA & & \\
\hline M13* & $4.05 \mu$ & $0.16 \mu$ & 21 & $3.96 \mu$ & $.06 \mu$ \\
\cline { 4 - 6 } & & & 23 & $4.05 \mu$ & $0.06 \mu$ \\
\hline
\end{tabular}

" Dual gain
Table 3 LWIR Bands Compared

\begin{tabular}{|l|cc|c|c|c|}
\hline \multicolumn{3}{|l|}{ VIIRS } & \multicolumn{3}{|l|}{ MODIS } \\
\hline Band & Band & Band & Band & Band & Band \\
Name & Ctr & Width & $\#$ & Ctr & Width \\
\hline M14 & $8.55 \mu$ & $0.3 \mu$ & 29 & $8.55 \mu$ & $0.3 \mu$ \\
\hline M15 & $10.8 \mu$ & $1.0 \mu$ & 31 & $\begin{array}{c}11.03 \\
\mu\end{array}$ & $0.5 \mu$ \\
\hline M16 & $12.0 \mu$ & $1.0 \mu$ & 32 & $\begin{array}{c}12.02 \\
\mu\end{array}$ & $0.5 \mu$ \\
\hline I5 & $11.5 \mu$ & $1.9 \mu$ & & & \\
\hline
\end{tabular}

absence of sounding bands (MODIS 31-36 $(13.2-14.1 \mu)$ on VIIRS since that capability is met by CrIS. Additionally, the ozone band (MODIS band 30 at $9.58 \mu$ ) is not needed since that data is available from a variety of other sources. The SST bands on VIIRS are significantly broader than those on MODIS.

\section{SPATIAL AND GEOMETRIC PROPERTIES}

Table 4 shows that the intrinsic spatial resolution of VIIRS at nadir is generally better than that of MODIS.

Table 4 Spatial Resolutions Compared

\begin{tabular}{|ll|ll|}
\hline VIIRS & \multicolumn{3}{l|}{ MODIS } \\
\hline Name & $\begin{array}{l}\text { GSD (m) } \\
\text { Nadir }\end{array}$ & Band & $\begin{array}{l}\text { GSD (m) } \\
\text { Nadir }\end{array}$ \\
\hline M1 & 742 & 8 & 1,000 \\
M2 & 742 & 9 & 1,000 \\
M3 & 742 & 10 & 1,000 \\
& & 3 & 500 \\
M4 & 742 & 12 & 1,000 \\
I1 & 371 & 4 & 500 \\
M5 & 742 & 13 & 250 \\
M6 & 742 & 15 & 1,000 \\
M7 & 742 & 16 & 1,000 \\
I2 & 371 & 2 & 250 \\
\hline M8 & 742 & 5 & 500 \\
M9 & 742 & 26 & 1,000 \\
M10 & 742 & 6 & 500 \\
I3 & 371 & & \\
M11 & 742 & 7 & 500 \\
M12 & 742 & 20 & 1,000 \\
I4 & 371 & & \\
M13 & 742 & 21 & 1,000 \\
\hline M14 & 742 & 23 & 1,000 \\
M15 & 742 & 29 & 1,000 \\
M16 & 742 & 31 & 1,000 \\
I5 & 371 & 32 & 1,000 \\
\hline
\end{tabular}


VIIRS uses a pixel aggregation scheme based on a very small instantaneous field of view $(262 \mathrm{~m}$ $\mathrm{x} 742 \mathrm{~m}$ at nadir for the moderate resolution bands), resulting in less integration drag than found in MODIS. See Table 4.

The pixel aggregation reduces the pixel growth such that at edge of scan (1,500 km from nadir) the $742 \mathrm{~m}$ pixels will be $1.6 \mathrm{~km} \times 1.6 \mathrm{~km}$. MODIS $1 \mathrm{~km}$ nadir pixels grow to $2 \mathrm{~km}$ by $6 \mathrm{~km}$ at edge of scan (1,150 km from nadir).

Both MODIS and VIIRS data can be geolocated to $\pm 200 \mathrm{~m}(3 \sigma)$ with post processing. Band-toband co-registration is better than 0.2 pixels.

\section{RADIOMETRIC PROPERTIES}

Signal to noise is generally comparable between MODIS and VIIRS. Table 5 shows the specification for VIIRS and MODIS at nadir. VIIRS values reflect the aggregation of 3 pixels. Note that no adjustment has been made for differing pixel sizes.

Radiometric resolution is also similar, with both sensors transmitting 12-bit digitization and using similar values for maximum radiances. On-board calibration is nearly identical, with both sensors utilizing a single black body source, a solar diffuser and a solar diffuser stability monitor. The extensive on-board Spectral Radiometer and Calibration Assembly (SRCA) found on MODIS is not on VIIRS.

\section{CONCLUSION}

Other design features of interest include the use of a rotating telescope in place of the large MODIS paddle-wheel scan mirror, a greatly reduced parts count, and all reflective fore-, relay- and aft-optics.
Table 5 Signal to Noise

\begin{tabular}{|ll|ll|ll|}
\hline VIIRS & \multicolumn{5}{|c|}{ MODIS } \\
\hline Band & & L $_{\text {typ }}$ & & L $_{\text {t;p }}$ \\
Ctr & Gain & $\mathbf{T}_{\text {twn }}$ & SNR & $\mathbf{T}_{\text {twp }}$ & SNR \\
\hline $\mathbf{4 1 2}$ & High & 45 & 764 & 45 & 880 \\
& Low & 200 & 1781 & & \\
$\mathbf{4 4 5}$ & High & 40 & 977 & 42 & 838 \\
& Low & 56 & 2456 & & \\
$\mathbf{4 8 8}$ & High & 32 & 1067 & 32 & 803 \\
& Low & 52 & 3050 & 35 & 243 \\
$\mathbf{5 5 5}$ & High & 21 & 932 & 21 & 750 \\
& Low & 29 & 3275 & 29 & 228 \\
$\mathbf{6 4 5}$ & Single & 22 & 335 & 22 & 129 \\
$\mathbf{6 7 2}$ & High & 10 & 645 & 10 & 914 \\
& Low & 22 & 3346 & & \\
$\mathbf{7 5 1}$ & Single & 10 & 557 & 10 & 600 \\
$\mathbf{8 6 5}$ & High & 6 & 864 & 6 & 517 \\
& Low & 25 & 3714 & 25 & 201 \\
$\mathbf{8 6 5}$ & Single & 25 & 435 & 25 & 201 \\
\hline $\mathbf{1 . 2 4}$ & Single & 5 & 228 & 5 & 74 \\
$\mathbf{1 . 3 7 8}$ & Single & 6 & 257 & 6 & 150 \\
$\mathbf{1 . 6 1}$ & Single & 7 & 867 & 7 & 270 \\
$\mathbf{1 . 6 1}$ & Single & 7 & 149 & & \\
$\mathbf{2 . 2 5}$ & Single & 0 & 26 & 1 & 111 \\
$\mathbf{3 . 7 4}$ & Single & 270 & 146 & 300 & 470 \\
$\mathbf{3 . 7 4}$ & Single & 270 & 46 & & \\
$\mathbf{4 . 0 5}$ & High & 300 & $\mathbf{8 9 4}$ & 300 & 364 \\
& Low & 380 & 1035 & & \\
\hline $\mathbf{8 . 5 5}$ & Single & 270 & 1628 & 300 & 1066 \\
$\mathbf{1 0 . 8}$ & Single & 300 & 2233 & 300 & 1362 \\
$\mathbf{1 2 . 1}$ & Single & 300 & 2428 & 300 & 1475 \\
$\mathbf{1 1 . 4 5}$ & Single & 210 & 91.7 & & \\
\hline & & & & & \\
\hline
\end{tabular}

VIIRS represents the first step in converting EOS-era state-of-the art research sensors into operational sensors that can serve the needs of both the operational and research communities. It is a significant step forward in NASA's plans to maintain needed systematic measurements and to fulfill its role to inject technology into the NPOESS at appropriate times. 